\title{
AUTOGESTÃo POPULAR E AUTOEDUCAÇÃO: A EXPERIÊNCIA DE OAXACA - MÉXICO (2006)
}

ESTRADA SAAVEDRA, M. El Pueblo ensaya la revolución. La APPO y el sistema de dominación oaxaqueño. 1. ed. Ciudad de México: El Colégio de México, Centro de Estudios Sociológicos, $2016^{1}$.

Resenhado por: Cláudio Rodrigues da Silva ${ }^{2}$

"El Pueblo ensaya la revolución. La APPO y el sistema de dominación oaxaqueño" é mais uma obra de Marco Estrada Saavedra, Professor do Centro de Estudios Sociológicos de El Colegio de México e autor - além de artigos e capítulos atinentes à temática dos movimentos sociais - de livros, tais como, "Die deliberative Rationalität des Politischen" (2002), "La comunidad armada rebelde y el EZLN" (2007) e "Sistemas de protesta" (2015). Ressalta-se, ainda, a sua participação como editor do livro "Chiapas después de la tormenta. Estudios sobre economía, sociedad y política" (2009).

Publicado em 2016 por El Colégio de México, esse livro, que vem acompanhado de um DVD complementar relativo à Asamblea Popular de los Pueblos de Oaxaca (APPO) também conhecida como Comuna de Oaxaca -, aborda diferentes aspectos relacionados a esse Movimento ${ }^{3}$ de setores das classes trabalhadoras. A Assembleia teve como uma espécie de gérmen a mobilização, que ocorre anualmente, de professores da Sección XXII do Sindicato Nacional de Trabajadores de la Educación (SNTE), no ano de 2006, em Oaxaca, Capital do Estado homônimo, na Região Sudeste do México.

O impasse nas negociações entre essa Organização e o governo de Oaxaca resultou num conflito que alterou política, econômica e culturalmente a dinâmica dessa capital. $\mathrm{O}$ Estado opta por não dialogar e por reprimir o Movimento dos professores, que conquista o apoio de vários setores das classes trabalhadoras, originando, assim, a APPO. Os appistas reagem a esse posicionamento do Estado e, após intensas disputas com autoridades estatais, passam a controlar diversos pontos da cidade, organizações ou instituições, estatais ou não, de Oaxaca. O Estado, por sua vez, adota novas medidas, majoritariamente repressivas, para tentar resolver a questão - desde uma perspectiva institucional - da ingovernabilidade. APPO, Estado e setores sociais contrários a essa Assembleia dos trabalhadores protagonizam, ao longo desse Movimento, vários episódios envolvendo o uso tanto da força ideológica quanto da força física.

O livro, resultado de um trabalho de campo levado a termo entre 2008 e 2014, aborda, de forma processual, diferentes aspectos dessa Assembleia, inclusive no que se refere a 
antecedentes, constituição, atividades e desdobramentos, atores sociais envolvidos e seus posicionamentos, bem como contradições, confrontos, conflitos ou disputas, tanto entre APPO e Estado quanto entre setores ou organizações componentes desse Movimento, que passou por várias alterações, seja em termos de demandas seja em termos de organizações ou atores sociais envolvidos.

Fundamentado num amplo conjunto de fontes bibliográficas, documentais e empíricas, o livro totaliza 623 páginas - sem contabilizar os Anexos - e é composto por oito capítulos, além da Introdução, das Conclusões, das Referências e dos Anexos. Apresentamse, a seguir, os títulos dos capítulos e dos tópicos neles abordados.

No capítulo I, intitulado "Preludio. La APPO como sistema de protesta", o autor apresenta os seguintes tópicos: a) Complejidad y diferencia; b) Los subsistemas especializados de la APPO; e c) Más allá de la unidad y la identidad.

O segundo capítulo, denominado "El sistema educativo oaxaqueño y la Sección XXII del SNTE", apresenta os assuntos a seguir: a) La desconcentración del sistema educativo mexicano (1980 - 1989) e b) La incorporación del MDTEO [Movimiento Democrático de los Trabajadores de la Educación de Oaxaca] a la gestión del sistema educativo oaxaqueño: el IEEPO [Instituto Estatal de la Educación Pública de Oaxaca] y la Sección XXII (1990 1996).

"El sindicato de maestros y el movimiento democrático magisterial" é o terceiro capítulo do livro. Nele Estrada Saavedra trata dos seguintes temas: a) La dualidad organización-sistema de protesta de la Sección XXII; b) La organización de la Sección XXII del SNTE; c) ¡Todo el poder a las bases! La organización del MTDEO; d) Participación de las bases magisteriales; e) El "libro rojo": los principios rectores; f) Las corrientes políticosindicales; e g) ¿Con las bases todo, en contra las bases nada? La colonización del MTDEO por parte de la Sección XXII del SNTE.

No capítulo quarto, que tem por título "El magisterio oaxaqueño y la constitución de la APPO", o autor aborda as questões a seguir: a) Charrismo sindical democrático: la corrupción en el CES [Comité Ejecutivo Seccional] de la Sección XXII; b) Hacia la refundación del MTDEO: el Primer Congreso Político de la Sección XXII; c) Coordinación de la solidaridad y la defensa de derechos: frentes y coaliciones de sindicatos, organizaciones populares y no gubernamentales en Oaxaca y México; d) El pueblo agraviado: el estilo de gobernar de Ulises Ruiz Ortiz; e) Convergencias: la APPO antes de la APPO; f) El plantón magisterial y el desalojo del 14 de junio de 2006; g) Los maestros y el pueblo; h) La lógica de las organizaciones populares de masas; i) El subsistema de movilización coordinada de masas; j) El subsistema de dirección política; k) La constitución del Espacio Civil; 1) El subsistema de planificación; e m) Problemas y tensiones entre los integrantes del Espacio Civil y las organizaciones populares de masas de la APPO. 
Em "Que se escuche la voz del pueblo: la difusión mediática de la protesta", quinto capítulo, são apresentados os temas seguintes: a) Noticias incómodas para el régimen; b) Radiactividad; c) El subsistema de difusión mediática; d) Recuperando la palabra; e) La operación de la difusión de la protesta; f) La convulsión de la lógica mediática; g) Politizando los medios; h) Interferencias comunicativas: los conflictos al interior de los medios de difusión; i) La Coordinadora de Mujeres Oaxaqueñas $1^{\circ}$ de Agosto;j) Los medios de difusión y la represión; k) Vociferando: Radio Ciudadana y la contraofensiva mediática del gobierno de Oaxaca; e l) Unidad en la diferencia: la perspectiva de observación de los medios appistas.

No sexto capítulo, "El pueblo ensaya la revolución: las barricadas como subsistema de seguridad", os pontos abordados são: a) Vigilia; b) El subsistema de seguridad; c) Incursiones en aquelarre: etnografía de las barricadas; d) La Comuna de Oaxaca: el proyecto político, la utopía y el pueblo; e) Lógicas espaciales, identitarias y de cambio de las barricadas; f) Mecanismos de comunicación y coordinación entre la APPO y las barricadas; g) Las dos APPO: tensiones intrasistémicas; h) El machismo-leninismo: las maestras en contra del patriarcalismo sindical; e i) De la ciudad tomada a la ciudad trastornada y destruida.

"Resistencia visual: los artistas urbanos y la protesta simbólica" é o sétimo capítulo do livro, no qual são abordados os seguintes assuntos: a) Incursiones nocturnas del crew; b) Historia y orígenes sociales y profesionales de los colectivos Arte Jaguar, Asaro y Lapiztola; c) El proceso de politización de los artistas urbanos; d) El subsistema de la protesta simbólica; e) El colectivo como forma de trabajo de los artistas; f) El arte como instrumento de la lucha política; g) Muros intervenidos como parte de la esfera de vida pública autónoma; h) Las transformaciones del arte urbano durante el conflicto; i) Arte y política después de 2006; j) El sistema del arte y la protesta gráfica; e k) Entre la barricada y la galería: las vanguardias y sus detractores.

Em “Apocalipsis: la violencia política en el conflicto de 2006”, oitavo capítulo, os tópicos discutidos são: a) ¡Oaxaca libre!; b) ¡Hasta la victoria siempre! Los encuentros y desencuentros entre la Segob [Secretaría de Gobernación] y la APPO; c) De la violencia al terror: la contraofensiva gubernamental y el sistema interinstitucional de represión; e d) La defensa jurídica como respuesta al restablecimiento del orden y el Estado de derecho.

"Conclusiones: dominación y conflicto en Oaxaca" encerram a parte nuclear do livro. Estrada Saavedra trata das seguintes questões: a) La conformación histórica del sistema de dominación oaxaqueño; b) ¿El estilo de gobernar de Ulises Ruiz Ortiz o la lógica sistemática autoritaria?; c) La Comuna de Oaxaca y el sistema de dominación; e d) La reforma educativa, la Sección XXII y la APPO.

Nos cinco "Anexos" o autor apresenta: I) Cuadros sociodemográficos de Oaxaca; II) Cuadros elecciones locales y federales en Oaxaca; III) Conflictos municipales en Oaxaca 


\section{Revista HIISTEYIDBR On-line}

(2006); IV) Conformación de asambleas municipales; V) La APPO en las regiones oaxaqueñas; e VI) Las ocho regiones de Oaxaca.

Considera-se que o autor aborda uma temática pertinente e atual, devido, entre outros fatores, à abrangência e à repercussão, em âmbitos nacional e internacional, da APPO, bem como a sua relevância - que transcende aquela conjuntura - para a história recente dos Movimentos ou das lutas sociais levadas a termo por diferentes setores das classes trabalhadoras em diversos países ou continentes.

Como pontuado, no caso em tela, a mobilização de professores por demandas eminentemente trabalhistas torna-se um Movimento - a APPO - composto por variados setores das classes trabalhadoras. Os appistas rechaçam a política tradicional e, por intermédio das assembleias populares, colocam em prática outra forma de gestão de organizações ou instituições da sociedade, baseando-se em princípios coletivistas e autogestionários. Dessa forma, a APPO contribui para problematizar desafios, limites, contradições e potencialidades da auto-organização, da mobilização e da união de diferentes frações das classes trabalhadoras para fins de alteração da correlação de forças, de forma a lograr avanços ou conquistas no que se refere a suas demandas.

O livro possibilita inferências ou estabelecimento de relações, dentre outras áreas, com a História da Educação, principalmente no que se refere a iniciativas ou demandas históricas de alguns dos principais movimentos sociais das classes trabalhadoras que, já no século XIX, não sem contradições ou condições adversas de variadas ordens, resistiam apresentando ressalvas ou mesmo recusando - ao ensino na perspectiva oficial, demandando ou colocando em prática projetos de autoeducação, disputando, assim, com o Estado ou com as classes dominantes a educação dos trabalhadores. Exemplificam isso proposições ou projetos levados a termo por anarquistas, cartistas britânicos, marxistas, socialistas utópicos (com destaque para os owenistas) e, na atualidade, pelo Movimento Zapatista (México) e pelo Movimento dos Trabalhadores Rurais Sem Terra (Brasil), entre outros.

Além de apresentar registro sistematizado e problematizações de principais características ou implicações da APPO, o livro propicia, direta ou indiretamente, aportes para reflexões acerca de diversos aspectos da educação, para além das fronteiras mexicanas ou da conjuntura da Comuna de Oaxaca. Entre esses aspectos está, por exemplo, a histórica consigna de alguns movimentos sociais de trabalhadores, qual seja, a gestão democrática, que coloca sob questionamento quem e como são decididos os objetivos e a concepção de educação.

O livro contribui, ainda, com dados para reflexões sobre a relação necessária entre sociedade e educação, principalmente no que se refere à complexidade e aos desafios das lutas sociais das classes trabalhadoras - como, por exemplo, a união entre diversas frações dessas classes -, às concepções de democracia imperantes em algumas de suas organizações, 


\section{Revista HIISTEYIDIR On-line}

assim como no que tange à articulação orgânica entre classes sociais e outras categorias analíticas, entre elas, cultura, gênero e etnia.

Os dados - a partir de aportes empíricos - apresentados no livro são importantes, em especial numa conjuntura de acirramento de controles e de disputas pela hegemonia na área da educação, seja entre diferentes classes sociais seja entre suas frações, o que implica, da parte das classes dominantes ou do Estado, a necessidade de controlar, de variadas formas, os trabalhadores dessa área. Controlar as condições de trabalho docente - formação, ingresso, ascensão, permanência, avaliação, salário, entre outros - é um fator fundamental para isso, pois esses quesitos são, em última instância, consoantes com a concepção de educação hegemônica vigente em dada formação social.

Há uma relação indissociável entre sociedade e educação, assim como entre as ditas esferas política, econômica e cultural. A educação cumpre papel-chave na reprodução da ordem social vigente na formação social que a concebe. Assim, em hipótese alguma o Estado ou as classes dominantes prescindem do controle da educação - em todos os seus aspectos ou fases: concepção, gestão e execução -, principalmente sobre o processo e sobre o produto do trabalho dos professores, responsáveis, em última análise, pela operacionalização do currículo estabelecido.

A APPO coloca em evidência a importância e a necessidade de mobilizações simultâneas que articulem, de forma orgânica, demandas mais imediatas/específicas de diferentes segmentos das classes trabalhadoras com demandas mais mediatas/amplas do conjunto dessas classes. Essa articulação visa principalmente a conquista de adesões ou de apoios de massivos de setores dessas classes para resistências ou transformações nos âmbitos político, econômico e cultural, inclusive em relação às políticas ou às reformas educacionais concebidas em consonância com diretrizes de agências internacionais. Ressalta-se que essas reformas têm entre seus principais desdobramentos o agravamento da precarização das condições de trabalho docente, a intensificação dos controles - em especial por intermédio de avaliações ou rankings -, a mercantilização, bem como a adequação da educação às, entre outros quesitos, demandas do sistema produtivo.

Determinados Movimentos, coletivos ou lutas sociais configuram-se como uma das principais instâncias de autoeducação - no sentido lato, ou seja, para além da educação escolar - das classes trabalhadoras, haja vista que nesses espaços ou atividades ocorre ou tende a ocorrer a experimentação dos princípios da autogestão e, por conseguinte, de desafios, de contradições e, principalmente, de potencialidades implicadas com a implementação, ainda que em caráter germinal, de lógicas divergentes ou antagônicas à sociabilidade hegemônica. Exemplifica isso a APPO, que, como pontuado, ao lado de outras iniciativas, como, por exemplo, dos Zapatistas e dos Sem Terra, configura-se como uma das mais importantes experiências autogestionárias recentes levadas a termo por organizações das classes trabalhadoras. Ademais, esses Movimentos, ainda que apresentem aspectos 
convergentes, têm, também, por várias razões, diferenças significativas entre si, o que possibilita, em alguma medida, a realização de análises ou cotejamentos de suas táticas, de suas estratégias ou de resultados por eles pretendidos ou alcançados.

A autoeducação é um quesito-chave para o desenvolvimento de projetos autogestionários. Porém, tanto projetos de autogestão quanto projetos de autoeducação das classes trabalhadoras são, em última instância, incompatíveis com os fundamentos do sistema do capital, inerentemente heterogestionário e pautado por relações hierárquicoverticais. Isso potencializa os desafios para implementação ou continuidade dessas iniciativas. Experiências como as mencionadas são, inclusive pelas contradições enfrentadas, legados teórico-práticos de inestimável valor para o processo visando à emancipação das classes trabalhadoras. O livro de Estrada Saavedra contribui para a compreensão e para a difusão da experiência da APPO, que instiga a análises a partir de outras perspectivas teórico-metodológicas.

\section{Notas}

\footnotetext{
${ }^{1}$ Os títulos dos capítulos e dos tópicos neles constantes são apresentados literalmente e em espanhol, língua original do livro, com vistas a propiciar à/ao leitor/a uma noção panorâmica dos temas discutidos pelo autor. Os dados entre colchetes apresentam o significado das siglas presentes em títulos de capítulos ou de tópicos do livro.

${ }^{2}$ Doutorado em Educação no Programa de Pós-Graduação em Educação da Faculdade de Filosofia e Ciências da Universidade Estadual Paulista (UNESP).

${ }^{3}$ Estrada Saavedra categoriza a APPO como "sistema de protesta". No entanto, opta-se, neste texto, por apresentá-la como um Movimento de setores das classes trabalhadoras; em dados momentos a APPO é também mencionada como Assembleia.
}

Submetido em: 02/01/2018

Aprovado em: 26/06/2018

Publicado em: 27/06/2018 